Orbis Tertius, vol. XXIII, nº 27, e079, junio 2018. ISSN 1851-7811

Universidad Nacional de La Plata

Facultad de Humanidades y Ciencias de la Educación

\title{
1 de mayo en Tulchin: biografía y extravío
}

\section{Mónica Szurmuk *}

* Universidad de Buenos Aires, Argentina.

Cita sugerida: Szurmuk, M. (2018). 1 de mayo en Tulchin: biografía y extravío. Orbis Tertius, 23 (27), e079. https://doi.org/10.24215/18517811e079

(c) (i) Esta obra está bajo licencia Creative Commons Atribución-NoComercial-Compartirlgual 4.0 Internacional http://creativecommons.org/licenses/by-nc-sa/4.0/deed.es AR 


\title{
1 de mayo en Tulchin: biografía y extravío
}

\author{
Mónica Szurmuk \\ Universidad de Buenos Aires, Argentina
}

\section{RESUMEN:}

En este texto parto de mi experiencia personal en la escritura de una biografia intelectual de Alberto Gerchunoff para describir ciertas particularidades del género biográfico y su relación con la escritura autobiográfica y con la crítica literaria. Propongo pensar en el extravío como figura de la biografía. La biografía es un género que propone, como la vida misma, múltiples caminos, que se pueden seguir o no. Es un género de la realidad pero también es un género de la corporalidad. Si todo trabajo intelectual nos atraviesa, la biografía se nos instala en el cuerpo y nos invita a releer nuestra propia vida. ¿A qué le damos importancia? ¿A qué no?La biografia es la que escribe el biógrafo y hay tantas posibilidades biográficas como biógrafos. Si bien hay datos que coinciden, el mundo textual que creamos para nuestro personaje refleja nuestras propias predilecciones. ¿Qué fuentes usar?, ¿cómo dar cuenta de la subjetividad de la voz que cuenta la vida del/de la otro/a?, ¿a quién leer?, ¿qué saber?, ¿qué ignorar?

Palabras Clave: biografia - Alberto Gerchunoff - escrituras delyo .

\section{Abstract:}

The starting point of this text is my own personal experience writing an intellectual biography of Alberto Gerchunoff in order to describe certain characteristics of the biographical genre and its relation with autobiographical writing and literary criticism. I posit that "going astray" is a useful figure to speculate about biography. Biography is a genre that puts forth several alternative paths to be taken, just as life itself does. It is a genre of reality but also a genre of corporality. If all intellectual work goes through our subjectivity, biography becomes embodied in us and invites a rereading of our own personal history. What do we prioritize? What do we overlook? A biography is a personal interpretation of a life and there are as many biographies of the same figure as there are biographers. While it is true that concrete data coincides, the textual world we create for our character reflects our own predilections. What sources to use? How to account for the subjectivity in the voice that narrates the life of another? Who do we read? What do we know? What do we forget?

KEYWORDS: biography - Alberto Gerchunoff - autobiographical writings.

A lo largo de diez años y paralelamente con otros proyectos académicos escribí una biografía intelectual de Alberto Gerchunoff. No sabía que iba a escribir una biografía cuando volví a leer a Gerchunoff. Aprendí a escribir una biografía en el acto de escribir y hurgando en las experiencias de otros. Creo que si hubiera conocido mejor el género la hubiera escrito más rápido, en menos tiempo, con menos sobresaltos. Creo, sin embargo, que este camino hacia el género me permitió imprimirle mi propia marca. Escribí ese texto desde la intuición y el extravío, no desde el oficio.

Mi biografía de Gerchunoff fue una anomalía en mi propia vida académica: no firmé contrato por adelantado, era un libro que tenía prometido, no tenía fecha de publicación. Tampoco supe hasta muy avanzada la investigación si iba a escribirlo en inglés o en castellano. Fue un libro que me acompañó en dos desplazamientos -de Estados Unidos a México y de México a la Argentina. Iniciado al despedirme de mi trabajo en Estados Unidos, este libro fue el proyecto con el que entré al Conicet y volví a la Argentina y que me permitió reflexionar sobre "la patria", concepto que cerró mi primer libro, el cual fue publicado en inglés en Estados Unidos en el año 2000. Investigar a Gerchunoff me abrió también el mundo de Europa Central y Oriental, espacio ineludible para pensar la primera mitad del siglo XX, el sitio donde se desencadenó la barbarie nazi y también donde se desmoronaron las utopías de fines del siglo XIX. Escribir la vida de Alberto Gerchunoff significaba escribir la historia de un niño nacido en la zona de exclusión del Imperio Ruso que 
se transformó en uno de los periodistas más importantes de la Argentina, un escritor de bestsellers y un político a nivel internacional, la historia de un niño que presenció a los siete años el asesinato de su padre en el campo argentino y cuyo canto al lugar de esta muerte se transformó en el texto fundamental del judaísmo latinoamericano.

\section{Extravío: 1 de mayo de 2012, Ucrania}

Extravío: definición del diccionario de la Real Academia Española:

1. tr. Perder algo, o no saber u olvidar dónde se encuentra. U. t. c. prnl.

2. tr. Dejar vagar la vista o la mirada sin fijarlas en un punto determinado.

3. prnl. Dicho de una persona: Perder el camino o la orientación.

4. prnl. Dejar la carrera y forma de vida que se había empezado y tomar otra distinta. U. m. en sent. peyor.

El 1 de mayo de 2012 viajé desde Vinnitsia a Tulchin, pueblo de la actual Ucrania donde Alberto Gerchunoff pasó parte de su infancia. Me acompañaban mi amiga Claudia Minoliti y Alejandra Wasylyk, empleada de la Embajada Argentina en Kiev que hacía las veces de traductora y que se había entusiasmado con este viaje de pesquisa y le estaba dedicando el fin de semana largo. Hacia el mediodía y bajo el rayo del sol, Tulchin apareció en medio de la ruta vacía, una pampa ucraniana que recién se liberaba de la nieve. La entrada era majestuosa, cercada por un palacio con dos alas, construido por los condes polacos Potoski que luego de la anexión de Polonia al Imperio Ruso en 1793 pasaron a estar al servicio de Catalina la Grande. Estos palacios estaban semiderruidos cuando una mañana de 1890 partieron los Gerchunoff hacia la Argentina y fueron los últimos recuerdos que se llevó el pequeño Abraham ben Gershon Gerchunoff -quien en Argentina sería conocido como Alberto Gerchunoff-de ese pueblo tapado de nieve que transformaría en figura literaria y que aparecería a menudo en su obra, frecuentemente en contraste con el idealizado paisaje entrerriano. En 2012 los palacios estaban en proceso de reconstrucción, en ruinas también, como si ese transcurrir del escombro fuera un estado permanente. Pensé en una figura que usé a menudo para hablar de la obra de Gerchunoff: media res, ese estado de indefinición, ese entrar a un texto como si ya se habitara. Algo de eso pasaba en estos palacios que más de 100 años después parecían indicar que todo seguía igual.

Envalentonada por la constatación de esta cierta permanencia (los palacios seguían allí, este era efectivamente el lugar de la infancia), emprendí el recorrido por Tulchin usando los escritos de Gerchunoff como guía: su familia, dice, se instaló en una casa con un vasto jardín desde el cual se veía "una iglesia de torres agudas, en cuyo frente, un San Alejandro de bronce dorado solicitaba la admiración de los chicuelos" (Gerchunoff, "Autobiografía", 129). Tulchin estaba perpetuamente cubierta de nieve. Era, recuerda Gerchunoff, "una ciudad sórdida y triste, sin alumbrado ni aceras, cuyo lujo arquitectónico se reducía al palacio semiderruido de los condes de Bazá y a un edificio llamado La Buena, sitio de paseos dominicales".

Visitamos, por consiguiente, la Iglesia de San Alejandro. Caminamos por las calles, modernizadas ahora gracias a la afluencia producida por una fábrica de embutidos. Terminamos el recorrido en el cementerio judío ubicado sobre una colina con vista al pueblo. Este cementerio fue fundado poco tiempo después de que los Gerchunoff se marcharan a América y el mismo año en que se inauguró el cementerio judío de Moisés Ville donde fue enterrado el padre de Gerchunoff. Claudia, que hacía poco había perdido a su padre, se recostó entre las lápidas y lloró. Hacía mucho calor, unos 30 grados inusuales en la primavera ucraniana y estábamos cansadas, insoladas. Ya era mediodía. Estábamos regresando al pueblo cuando un cuidador nos contó que había un cementerio judío nuevo. Mis compañeras ya estaban muy cansadas y no podían seguir colina arriba para visitar este otro cementerio. Seguí sola.

Lo que parecía ser un camino sin desafíos, se transformó en un desconcertante rompecabezas. En lugar de subir, inexplicablemente bajé al pueblo, a un área de casas bajas, no muy diferente del barrio del conurbano 
bonaerense donde me crié. Me acerqué a dos hombres que estaban parados en la puerta de una casa para pedirles que me guiaran pero no me entendieron. Decidí probar suerte con una mujer joven que regaba un jardín lleno de flores acompañada de dos niños pequeños. Imitando la pronunciación de Alejandra dije en lo que me parecía ucraniano: "cementerio hebreo". La mujer no me entendía pero sonreía e intentaba. Nos presentamos: Tamara, Mónica. Mostré una a una todas las fotos que había tomado en el cementerio judío y la niña lo reconoció. Tamara, me intentó guiar, señalando con un dedo extendido el humo que cubría el pueblo. Yo sabía que el humo no me iba a guiar, que me iba a volver a perder. Seguramente el niño que había sido Gerchunoff hubiera sabido seguir el humo, como también lo hubiera podido seguir mi abuelo que nació en un pueblo a 200 kilómetros de Tulchin y que partió a la Argentina en algún momento de 1926. Después de una serie de conversaciones familiares se decidió que Vassily, el marido de Tamara, me llevaría en moto al cementerio nuevo. Después de estacionar la moto y subir una colina a pie, cuando quedamos frente a las modernas lápidas en mármol del nuevo cementerio judío, Vassily me preguntó a quién buscaba. ¿A quién buscaba yo en ese cementerio de Tulchin?

La respuesta resumida en un término repetido en varios idiomas, ninguno de los cuales Vassily hablaba, fue libro, como si la palabra libro pudiera explicar por qué ese feriado yo no lo pasaba regando un jardín, comiendo un asado, sino extraviándome en un pueblo del que no conocía el idioma, a miles de kilómetros del mío, de todos los míos. Varios textos han ahondado en las zonas de la vida judía del centro y del este de Europa como esos repositorios de una memoria ya inexistente: un lugar donde se busca todo lo que ya no está. Por ejemplo, el autor norteamericano Jonathan Safran Foer describe en Everything is Illuminated la historia de un viaje a Ucrania en busca de la mujer ucraniana que salvó la vida de su abuelo durante el exterminio nazi. La escritora chilena Cynthia Rimsky describe en Poste Restante su viaje a Ucrania en búsqueda del pueblo de sus antepasados. En ambos textos -en los que se combina lo ficcional y lo testimonial- los viajes son fallidos, ya que no se realizan los encuentros. La zona de residencia del Imperio Ruso, el Russian Pale, pareciera ser el lugar donde se va a buscar lo que no se encuentra, pero se sigue buscando, quizá porque allí sabemos que hay una memoria inaccesible, una memoria traumática que reconocemos en nuestros antepasados (Rimsky, Foer) o en Gerchunoff, el protagonista de mi biografía. Había llegado para saber algo de su infancia, de ese momento anterior a la vida argentina, y quizá lo que me llevaría sería la conciencia del silencio.

Fui a Tulchin porque me negaba a escribir una biografía de Gerchunoff que se iniciara en el puerto de Buenos Aires y dediqué mucho tiempo a entender el mundo anterior de Gerchunoff, los primeros siete años que transcurrieron en Europa. También estudié ídish para poder hurgar en los textos donde se escribía ese pasado que pensaba original. La literatura argentina ha abundado en el gesto de olvidar el origen. En su novela Lenta biografía, Sergio Chejfec lo transforma en motor narrativo. El padre del protagonista es un sobreviviente de la Shoá para quien el pasado europeo es a la vez lo que se quiere olvidar y de lo que se buscaría dejar testimonio, un laberinto de lo que no es decible pero que sin embargo se transforma en texto a través del hijo-narrador. El lugar del pasado traumático es un origen que al borrarse se escribe:

Supongo hoy, que es tan húmedo el aire y sin embargo no tiene importancia, que lo que para mi padre había sido un mar de padecimientos, nosotros lo imaginábamos como un pasado un tanto agitado que había tenido desde el comienzo el oculto destino de encontrarse aquí con nosotros: como si yo lo hubiese estado aguardando en Buenos Aires desde que empezó su periplo nefasto por Europa (Chejfec 1990: 24).

Ese pasado anterior me ayudaba a explicar por qué Gerchunoff dedicó los últimos años de su vida a la denuncia del nazismo y por qué, ya enfermo y descuidando su salud, viajó por toda América Latina para conseguir el voto de los países latinoamericanos para la creación del Estado de Israel. Volver a ese pasado era abandonar la dicotomía con la que se suele hablar de Gerchunoff a través de la conjunción "judío y argentino", o de la dicotomía "judío o argentino". La infancia europea me ayuda a explicar el arraigo enorme, el amor pasional de Gerchunoff hacia la Argentina. Necesitaba entender ese mundo anterior que en su destrucción lo lleva, en última instancia, a sacrificar lo que más valoraba, su vida misma, por encontrarle una tardía resolución. Del mismo modo que pasé horas imaginando cómo habría visto Gerchunoff la costa de 
Buenos Aires desde el barco, cómo vería el paisaje santafesino en el tren camino a Colonia Clara después del asesinato de su padre, quise imaginar la lectura diaria del desastre europeo desde los diarios de Buenos Aires. Su compromiso político con la creación del estado judío debe leerse en esta clave.

Como muchos de los niños judíos nacidos en el Imperio ruso hacia fines del siglo XIX, la vida de Gerchunoff transcurriría en América. Antes de la adolescencia, Gerchunoff se sacudió el pasado europeo y se metió de lleno en la vida argentina. Figura internacional, surgió de un contexto despojado y pobrísimo, inimaginable para muchos de sus compañeros de redacción y sus lectores. Nacido a miles de kilómetros del país donde creció, su infancia estuvo marcada por los vaivenes y las privaciones de la migración, y por el asesinato de su padre a pocos meses de desembarcar en Buenos Aires. A los trece años, cuando llegó a la Capital desde las colonias agrícolas judías de la provincia de Entre Ríos, Gerchunoff ya parecía haberse creado una vida propia y diferente.

La de Gerchunoff es una historia netamente argentina. Hay pocas sociedades en el mundo donde se podría concebir semejante aceleramiento del ascenso social no como excepción sino como norma. Los compañeros de juego de Gerchunoff en la escuela rural y en el conventillo de Buenos Aires llegaron a ser embajadores, catedráticos, escritores, médicos, directores de cine, empresarios y senadores. Recién llegado del campo, huérfano de padre y criado por una madre que nunca dominó el castellano, conoció a Bartolomé Mitre, ex-presidente de la nación y director del diario La Nación, donde publicaban las plumas más importantes de la lengua castellana y donde Gerchunoff mismo, todavía adolescente, publicó su primera crónica sobre su infancia en las colonias judías del Litoral. Se formó leyendo libros de la Biblioteca Socialista, armó una biblioteca propia ecléctica donde convivían la literatura española, la Biblia y los poetas centroeuropeos.

Propongo pensar en el extravío como figura de la biografía. La biografía es un género que propone, como la vida misma, múltiples caminos, que se pueden seguir o no. Es un género de la realidad pero también es un género de la corporalidad. Si todo trabajo intelectual nos atraviesa, la biografía se nos instala en el cuerpo y nos invita a releer nuestra propia vida. ¿A qué le damos importancia? ¿A qué no? La biografía es la que escribe el biógrafo y hay tantas posibilidades biográficas como biógrafos. Si bien hay datos que coinciden el mundo textual que creamos para nuestro personaje refleja nuestras propias predilecciones. ¿Qué fuentes usar? ¿cómo dar cuenta de la subjetividad de la voz que cuenta la vida del/de la otro/a? ¿a quién leer? ¿qué saber? ¿qué ignorar?

La clave principal de la biografía está en este equilibrio entre el campo de lo que el biografiado sabía y lo que el biógrafo ignora y por otro lado entre todo lo que sabe el biógrafo que el biografiado ignoraba. Inevitablemente la escritura de la vida retrata dos épocas: la que vivió el sujeto de la biografía y la que vive quien la produce. El destiempo temporal entre la experiencia y el registro de la experiencia es enorme y ningún biógrafo lo puede saldar. El ejercicio fundamental es estar atento a lo que el sujeto de la biografía sabía y también a lo que ignoraba. La biografía siempre es un género contrafáctico, que hurga en los espacios de la vida de otro, que horada preguntas, que intenta respuestas. Y en última instancia, es siempre una interpretación.

\section{Eugene, Oregon 2003. Los orígenes}

Ya había renunciado a mi puesto en la Universidad de Oregon cuando regresé a dictar un último seminario de Doctorado en colaboración con una colega especialista en literatura francesa, en el que estudiamos el período de la historia europea y argentina que va desde la Emancipación de los judíos después de la Revolución Francesa hasta el final de la Shoá a través de las reflexiones de algunos filósofos (Derrida, Lévinas, Bauman) y algunos textos literarios (Respiración Artificial de Piglia, La nave de los locos de Cristina Peri Rossi, Du côté de Chez Swann de Proust y textos de Lazare y Zola). Los gauchos judios en una reciente traducción al inglés se había transformado en un texto de relleno, en el programa, contrapunto de algunas lecturas francesas sobre la emancipación de los judíos en la Europa posterior a la Revolución Francesa. Para mi sorpresa, los estudiantes (quince en total, entre los que había estadounidenses, una irlandesa, dos franceses, dos italianos, un nigeriano, 
un costamarfilense, un argelino, una alemana) quedaron fascinados con Los gauchos judios a excepción de la única estudiante argentina que lo seguía considerando un texto escolar. Algunos (los africanos, la irlandesa) remarcaron la sensibilidad de Gerchunoff para describir el mundo rural. Había algo en este texto que se me escapaba y que podría definir como una cierta traducibilidad, un texto que leído fuera de su coyuntura y de las lecturas canónicas realizadas podía conseguir nuevos lectores. Era un texto que viajaba, que podía ser traducido, que podía paradójicamente escapar a lo que Franco Moretti ha llamado "el matadero de la literatura”.

Empecé a leer a Gerchunoff para ver qué se me escapaba. Encontré 16 libros, cientos de artículos periodísticos desperdigados en publicaciones de toda América y de Europa. Armé un proyecto de investigación de crítica literaria en el que Gerchunoff convivía con otros autores. En un viaje a Buenos Aires fui al archivo de Gerchunoff en el Instituto Ravignani y me encontré con lo que es el sueño de todo biógrafo: un grupo (desordenado pero prometedor) de papeles personales, invitaciones, fotos dedicadas, telegramas. Y a pesar de que todavía no era una lectora asidua de biografías, pensé que lo que yo quería decir de Gerchunoff podía articularse más exitosamente en una biografía que en un ensayo crítico. Llegué a esa conclusión leyendo a Gerchunoff mismo, quien fue un gran lector y escritor de biografías y de una deliciosa autobiografía.

\section{Escribir una vida}

A fines de 1913 Gerchunoff viajó a Europa con su mujer y sus dos hijas como representante del gobierno argentino en la Feria del Libro de Leipzig. Fue un regreso triunfal: el niño ruso inmigrante que había llegado al país sin hablar una palabra de castellano se había transformado en representante oficial del gobierno argentino y viajaba en primera clase en lugar de tercera, con pasaporte diplomático y cartas de presentación oficiales. Durante su estadía en Europa (a la que Gerchunoff se referiría como su saison en paradis) dictó conferencias sobre el Quijote en España, visitó a Proust y a miembros de la intelligentsia francesa en París, paseó con Lugones y Darío y pasó una larga temporada en Bélgica en la casa de Payró.

Hacia finales de esa estadía, en 1914, en París, escribió su autobiografía. Acababa de cumplir 30 años pero le parecía ya que su trayectoria podía ejemplificar la vida judía en los países modernos. Su relato de su vida toma como eje la emancipación de los judíos y se presenta como ejemplo. El manuscrito original escrito en apretada tinta violeta se conserva en el archivo del Instituto Ravignani. Ese texto me fascinó, especialmente porque registraba las correcciones, lo tapado, lo oculto. Me di cuenta de que la podía usar como una lente a través de la cual observar los primeros treinta años de la vida de Gerchunoff.

Sabía que Ana Korenfeld, la madre de Gerchunoff, había muerto en abril de 1913, unos pocos meses antes del regreso triunfal a Europa. Payró había registrado esta muerte en una carta desde Bruselas:

\footnotetext{
Me imagino cuánto la habrán llorado y la llorarán ustedes que la querían tan entrañablemente. Yo recordaré siempre la figura viva y enérgica de la anciana que casi del otro extremo del mundo había ido a seguir sufriendo en nuestro país quien comenzaba apenas la merecida recompensa de los años felices, en medio de sus hijos y sus nietos.

Mucho nos ha conmovido el hecho contado por Teresa de que la viejita se haya acordado afectuosamente de nosotros en sus últimos días, y lo agradecemos de todo corazón a su querida memoria. (Carta de Payró, 25 de abril de 1913, p.1)
}

No encontraba ningún escrito de Gerchunoff sobre esta muerte, ni en los papeles personales, ni en los textos literarios. Creía reconocer trazos de la figura de la madre en las biografías que él escribió. Le pregunté a Tulio Halperín Donghi, sobrino-nieto de Gerchunoff, sobre la muerte de su bisabuela. Halperín recordaba la herida en su abuela Sofía y recordaba (o había leído) que su bisabuela también había sido herida ese día. El mismo gaucho que había asesinado al padre de Gerchunoff había herido gravemente a su madre y a su hermana Sofía Gerchunoff de Halperín, quien sería la abuela de Tulio.

Releo la Autobiografía de Gerchunoff en búsqueda de alguna palabra sobre la madre. La versión que fue publicada en el libro Entre Ríos, mi país no incluye ninguna. Leo con detenimiento y atención el manuscrito. 
En la sección en la que se relata la mudanza de Moisés Ville a Rajil después de la muerte del padre encuentro unos tachones muy gruesos en medio de una sección dedicada a la madre y a su dolor frente a la viudez:

Mi madre que desde la trágica... de Moisés Ville no había vuelto a sonreír, [tachado] con abandonar el campo. Ella [y aquí los tachones se vuelven más gruesos]... a que yo estudie, a que no sea un simple colono (“Autobiografía”, p.17)

Vuelvo a leer este párrafo con una lupa potente. La imagen se va agrandando. A través de los tachones emergen con cierta claridad después de "ella" las palabras "que está bajo tierra". La frase hecha - "que está bajo tierra" - está tapada por trazos gruesos y enérgicos con el empeño del escritor que odia el lugar común, pero no puede encontrar otro modo de hablar de la pérdida. El lamento por la muerte de la madre, la tristeza, el duelo, no pudo encontrar lugar ni en este texto ni en otros.

Gerchunoff se dedicó a escribir vidas. Creía en la biografía como género pedagógico ejemplar y le tocó la tarea de escribir las necrológicas del diario La Nación. Escribió decenas de estas notas que suelen empezar en medias res ("En 1914, cuando Bergson fue elegido miembro de la Academia Francesa, se realizó en París, una encuesta sobre el valor de su obra filosófica" < Figuras 283>, "En una larga conversación que tuve con Aníbal Ponce, pocos días antes de que emprendiese su viaje a México..." < Figuras 327>) y terminan con una escueta vuelta al nacimiento en una fórmula en pluscuamperfecto ("Herbert George Wells había nacido en Bromley en 1866" < Figuras 244>) o en pretérito ("Máximo Gorki nació en Nijni-Novgodorov en 1868" $<$ Figuras 282>). En cada biografía, Gerchunoff se enfoca en cierto aspecto del personaje, cierta característica que define su personalidad, y hace que su voz privada cobre centralidad en el espacio público. Escribir una biografía es intuir lo que uno no puede contar del autor. Las biografías apócrifas, como las de Marcel Schwob, ponen esto de relieve iluminando una característica del biografiado, algo que lo hace humano, y dejando las demás en la sombra. Gerchunoff adoraba resaltar detalles pero también ubicar espacialmente a sus personajes: Stefan Zweig en su exilio brasilero, Proust en su casa parisina.

Dice Borges sobre Schwob: "Para su escritura inventó un método curioso. Los protagonistas son reales, los hechos pueden ser fabulosos o no, pocas veces fantásticos" (1996c: 486). Todos los biógrafos inventamos a la figura -de acuerdo a algunos datos necesarios, fabulando a veces sobre protagonistas reales- cuya vida nos da acceso a una historia anterior. Pensé a menudo en las pesadillas de Gerchunoff, las que quería adivinar y que quise ubicar cerca de la frase repetida de forma levemente diferente en las dos biografías que él escribió, ¿se cerrará nuevamente la puerta del gueto? Benjamin Moser, biógrafo de Clarice Lispector imaginó que toda la literatura de Lispector podría reducirse a un momento inicial, esa tierra ucraniana, no lejos del lugar donde nació Gerchunoff.

A Gerchunoff le interesaba particularmente escribir sobre escritores. Sostenía que hay un secreto que transita toda la obra de un escritor y que la única manera de acercarse a un descubrimiento es a través de la lectura de esa vida. Dice en un texto de 1926:

Júzgame por las pequeñas cosas, júzgame por las palabras que no entiendas. En ellas encierro lo que no puedo decir y me está ahogando con el júbilo o con el dolor, porque es secreto, es el secreto sagrado de cada vida, y lo que hacemos y decimos es para ocultarlo más, a fin de que lo adivine únicamente quien debe adivinarlo (1926: 12).

Sus dos libros biográficos fueron sobre figuras similares a él: hombres judíos que se aventuraron en campos que supuestamente les estaban vedados, que fueron figuras fundamentales en sus campos de acción. Heine, el mejor poeta alemán; Spinoza, el filósofo de la modernidad. Lo que estos dos hombres compartían en la mirada de Gerchunoff era un secreto que estaba relacionado con su ser judíos, con la posibilidad de que la puerta del gueto se volviera a cerrar. Según María Zambrano: "Como quien pone una bomba, el escritor arroja fuera de sí, de su mundo, y por tanto de su ambiente controlable, el secreto hallado" (1934: 118). En Mal de archivo, Derrida hurga en el secreto, ese trazo de un texto que no se revela. En el archivo, sugiere el autor, se guarda lo que se percibe pero no se puede articular, en ese sentido el archivo preserva el futuro más que el pasado: el archivo habla al futuro, recoge algo que ya está en el presente y lo guarda para que alguien lo pueda leer en el futuro. Si el eje de la biografía de un escritor es el secreto y este secreto -además de variar según la época 
y los lectores- sólo puede encontrarse por medio del azar, entonces el extravío resultaría una buena manera de dar con él. El archivo habla al futuro, dice Derrida, recoge algo que ya está en el presente y lo guarda para que alguien lo pueda leer en el futuro. En su biografía de Véra Nabokov, Stacy Schiff anota varios sueños de su biografiada (2000: 198). Durante algunos años, nos cuenta Schiff, Vládimir Nabokov registaba en un cuaderno todos sus sueños y los de Véra, su esposa. ¡Qué biógrafa no querría contar con esta información!

\section{Espacios de la biografía.}

Según Walter Benjamin "la vida de un individuo está contenida en una de sus obras, en uno de sus hechos y en esa vida cabe una época entera" (1991: 347). Uno de los trabajos de la biografía fue volver a incluir a Gerchunoff en los espacios que transitó. Uno de los logros de Gerchunoff fue escapar de los espacios asignados: el gueto, la comunidad judía y abrirse a todo -la Universidad, el aula, la redacción del diario, la tribuna política, la Embajada-. Hizo todo eso guiado, además, por una férrea conducta ética: rechazó cargos políticos, el nombramiento a la Academia Argentina de Letras, honores y premios.

Volver a ubicar a Gerchunoff era mirar el mundo de la primera mitad del siglo XX, tanto sus límites como sus posibilidades. Yo quería entender el mundo de la primera mitad del siglo XX en la Argentina y me parecía que Gerchunoff era el guía perfecto. Sentía que Gerchunoff había sido central en la primera mitad del siglo y luego había sido borrado con el paso del tiempo. Volver a centrarlo era revelar algunos espacios que habían quedado en la penumbra de los estudios historiográficos y literarios. Al regresarlo a los espacios en los que estuvo, se ordenaban también las figuras centrales a través de las cuales se cuenta la historia: Rubén Darío, Marcel Proust, Valle Inclán, Jorge Luis Borges, Gabriela Mistral, Victoria Ocampo, Alfonso Reyes. En el Instituto Mora de la ciudad de México, donde empecé a pensar a Gerchunoff, encontré un ejemplar de Los gauchos judios que había sido comprado por José Vasconcelos cuando era Ministro de Educación en el México postrevolucionario. Gerchunoff me iba abriendo caminos, aparecía en los temas que me interesaban, se colaba en una soirée en lo de Victoria Ocampo, en las tertulias de Mme. Geneviève Halevy en París y charlaba con Proust, recibía a los refugiados de la Guerra Civil española, les prometía trabajos a los expulsados de la Revolución Mexicana, le ofrecía publicarle un poema a Borges, poeta joven aún inédito. Gerchunoff tenía una erudición de pobre. Todo lo leía.

Es imposible recorrer los diarios y revistas de la primera mitad del siglo XX sin toparse con su nombre. Gerchunoff se multiplicaba: viajaba por todo el continente dando conferencias o reportando lo que veía para los lectores de La Nación; cocinaba, leía, traducía, iba al teatro, al cine. Según Baldomero Sanín Cano, Gerchunoff hablaba para unos pocos en Buenos Aires mientras lo escuchaba complacido el continente. Jorge Luis Borges afirmaba que Gerchunoff siempre encontraba la palabra justa y que hablaba con la misma precisión con la que escribía.

\section{Buenos Aires 1950-2015}

Nadie va a conocer el secreto desde el que hablo y el hecho de que lo diga no cambia nada. Jacques Derrida. Circumfession.

Elegir un lugar para morir es también elegir un lugar para vivir. Las revelaciones, afirma Cristina Peri Rossi, siempre son oscuras. En las horas en que me perdí en los mapas de la zona de residencia del Imperio Ruso donde nació Gerchunoff, en las incontables visitas a cementerios, en las bibliotecas y en la búsqueda infructuosa de la clínica psiquiátrica donde estuvo internada la hija menor de Gerchunoff, perseguía en realidad ese secreto, esa revelación que pudiera indicarme si la biografía le hacía justicia al personaje. Como señala Benoît Peeters, toda biografía "carece de su lector 'supremo': el que ya no está."

Empecé por el final. En la muerte y la certeza (creo) que Gerchunoff hubiera elegido morir en Buenos Aires. Termino hoy con el texto con el que empiezo la biografía: 
De haber podido elegir el lugar de su muerte quizá Alberto Gerchunoff hubiera elegido justamente la manzana del diario $L a$ Nación donde murió en plena calle el 2 de marzo de 1950 a los 66 años. Gerchunoff hizo de La Nación su hogar y su tribuna. Cultivó el castellano, conoció y amó la ciudad de Buenos Aires y se movió por sus recovecos haciéndola suya. Asombrado de que el cuerpo de Gerchunoff no hubiera sido identificado enseguida después de su muerte, Jorge Luis Borges lo tomó como una señal de cuánto había crecido Buenos Aires. Ya no es la gran aldea, afirmó, cuando un hombre tan porteño como Gerchunoff no es inmediatamente reconocido.

Gabriel Kantor, nieto de Gerchunoff, cuenta otra historia. Según él, su abuelo fue reconocido inmediatamente por los empleados del diario, por el canillita de la esquina, por los transeúntes de esa calle que Gerchunoff recorría a diario. Sus nietos Gabriel y Sofía, que estaban esperándolo para ir al cine a ver El espectro de la rosa, se enteraron de que el abuelo no iba a regresar unas horas después. Sofía lamenta que el abuelo haya caminado en dirección opuesta a su ruta habitual: de no haber sido así, hubiera sido reconocido inmediatamente, afirma. Quizá justo antes de morir Gerchunoff haya pensado en los chicos que lo esperaban. O probablemente haya recordado al chico que él había sido, el que presenció en un atardecer de Moisés Ville el asesinato de su padre. El último día que le tocó vivir completo, el 1 de marzo de 1950, Gerchunoff seguramente pensó a menudo en la muerte de su padre acaecida exactamente 58 años antes. Se habrá preguntado si el padre hubiera deseado morir en Moisés Ville, un rincón remoto de la pampa argentina; si hubiera elegido ser enterrado en el solitario cementerio del pueblo a muchos kilómetros y un mar de distancia del lugar en donde había nacido y donde estaban enterrados sus antepasados. En 1950, sin embargo, Gerchunoff ya tenía una certeza. La travesía dolorosa y final de sus padres a través del Atlántico había salvado a los cinco hijos que habían nacido del otro lado.

¿Dónde hubiera elegido nacer Gerchunoff? En las notas necrológicas aparecidas en los diarios de todo el continente se decía que había nacido en Entre Ríos, Santa Fe, Rusia, Ucrania, Rajil y Moisés Ville. Gerchunoff mismo alimentó mitos contradictorios con respecto a su lugar de nacimiento. En su libro más recordado -Los gauchos judios- narró su nacimiento en el Imperio Ruso, pero a menudo dijo ser entrerriano. De hecho en su foja de servicios del diario La Nación aparece de su puño y letra Villaguay como lugar de nacimiento.

Gerchunoff había llegado a Buenos Aires con sus padres y sus cuatro hermanos en algún momento del año 1890. Su nombre era Abraham Ben Gershon Gerchunoff6 y nunca había escuchado el castellano, esa lengua que haría propia. ¿Cómo habrá visto ese chico de cinco años a Buenos Aires desde el barco? Como Noé Cociovitch, posiblemente haya divisado primero "un puntito de la costa, del que asomaba un extremo de una chimenea” que era la zona de desinfección de la isla Martín García donde seguramente la delegación en la que llegó Gerchunoff pasó unos días en cuarentena.

¿Dónde empieza esta historia? Quizá en los ojos del niño escudriñando la costa o en un pasado anterior, que quedará encriptado para siempre en ese otro idioma, el ídish que Gerchunoff habló durante toda la vida y del que tradujo obras literarias al español, pero que desdeñó como idioma literario propio. En ese idioma, su padre soñó con la libertad y la emancipación. Una de las grandes paradojas de la vida de Alberto Gerchunoff fue el haber creado literariamente un campo armónico en el lugar en que su padre fue asesinado a pocos meses de su llegada. Esa creación literaria, el campo donde los judíos se transformaron en gauchos, le ganó un espacio en el canon literario latinoamericano. Pero había un paisaje anterior, el que fue retratado por la literatura en ídish que Gerchunoff tanto amaba, un entorno de nieve y ríos helados. En sus escritos volvió una y otra vez a ese paisaje.

Quiero detenerme en ese paisaje anterior, en ese lugar donde Gerchunoff aún no era huérfano. Deseo retomar esa geografía que los argentinos nunca entendimos y que quisimos olvidar erigiendo como pasado el vaivén de los barcos, la mirada que se pierde en el horizonte, la orilla dando la bienvenida.

\section{BIBLIOGRAFÍA}

Benjamin, Walter (1991). “Sur le concept d'histoire”, en Écrits français, París, Gallimard, pp. 347-350. 
Borges, Jorge Luis (1979). "Borges conversa sobre Gerchunoff”, en Alberto Gerchunoff, Figuras de nuestro tiempo,Buenos Aires, Babel, 1979, pp. 11-16.

Borges, Jorge Luis (1996a). Obras completas 1, Buenos Aires, Emecé.

Borges, Jorge Luis (1996b). Obras completas 2,Buenos Aires, Emecé.

Borges, Jorge Luis (1996c). Obras completas 4,Buenos Aires, Emecé.

Brown, Katherine (2004). A Biography of No Place: From Ethnic Borderland to Soviet Heartland, Cambridge, Harvard University Press.

Chejfec, Sergio (1990). Lenta biografia, Buenos Aires, Puntosur.

Cohen, Chester G. (1989). Shtetl Finder: Jewish communities in the 19th and early 20th centuries in the pale of settlement of Russia and Poland, and in Lithuania, Latvia, Galicia, and Bukovina, with names of residents, Bowie, Maryland, Heritage Books.

Degiovanni, Fernando (2000). "Inmigración, nacionalismo cultural, campo intelectual: El proyecto creador de Alberto Gerchunoff” en Revista Iberoamericana, vol. 66, núm. 191 (abril-junio de 2000), pp. 367-379.

Derrida, Jacques (1997). Mal de archivo. Una impresión freudiana. Madrid, Trotta.

Gerchunoff, Alberto (1926). Pequeñas Prosas. Buenos Aires, Gleizer.

GERCHUNOFF, Alberto. (1927). Enrique Heine: Elpoeta de nuestra intimidad. Buenos Aires-Madrid, Babel.

Gerchunoff, Alberto (1950). Entre Rios, mi pais. Buenos Aires, Futuro.

Gerchunoff, Alberto (1910). Los gauchos judios. La Plata, Talleres Gráficos Sesé.

Gerchunoff, Alberto (1914). “Autobiografía” en Archivo Gerchunoff, (Instituto Ravignani, Facultad de Filosofía y Letras, UBA). Caja 9-10-11.

Gerchunoff, Alberto (1979). Figuras de nuestro tiempo. Buenos Aires, Vernácula.

Katz, Steven (2007). The Shtetl: New Evaluations,Nueva York, New York University Press.

Klier, John (1986). Russia Gathers Her Jews: The Origins of the "Jewish Question",en Russia 1772- 1825,DeKalb, Northern Illinois University Press.

Nathans, Benjamin (2002). Beyond the Pale: The Jewish Encounter with Late Imperial Russia, Berkeley, University of California Press.

Ostrovskaya, Rita (1996). Jews in the Ukraine 1989-1994.Ostfildern, Cantz.

Oved, Iaacov (1976). "El trasfondo histórico de la ley 4.144 de Residencia”, en Desarrollo Económico 16, núm. 61 (abriljunio), pp. 123-150.

PAYRÓ, Roberto J. “Carta a Alberto Gerchunoff," Bruselas, 25 de abril de 1913. Archivo Alberto Gerchunoff. (Biblioteca del Instituto Ravignani. Facultad de Filosofía y Letras. Universidad de Buenos Aires), caja 20, n. 12.

Schiff, Stacy (2000). Véra (Mrs. Vladimir Nabokov), Nueva York, The Modern Library.

Stein, Sarah Abrevaya (2004). Making Jews Modern. The Yiddish and Ladino Press in the Russian and Ottoman Empires,Bloomington, Indiana University Press.

Szurmuk, Mónica (2005). "Diversidad, multiculturalismo y diferencia en la Argentina del Centenario: Los gauchos judíos de Alberto Gerchunoff” en Mabel Moran\#a y María Rosa Olivera-Williams (eds.), El salto de Minerva: Intelectuales, sociedad y Estado en Latinoamérica, Madrid-Franfkfurt, Iberoamericana-Vervuert, pp. 157-172.

Szurmuk, Mónica (2012). “El silencio de Gerchunoff” en Pensamiento de los Confines,Buenos Aires, Fondo de Cultura Económica, pp. 215-222.

Szurmuk, Mónica (2012). "El viaje a Europa de Alberto Gerchunoff" en Hispamérica, an\#o 41, núm. 121, Gaithesburgh, Maryland, pp. 25-37.

Szurmuk, Mónica (2010). "Home in the Pampas: Alberto Gerchunoffs Jewish Gauchos" en Simon Bronner (ed.), Jews at Home: The Domestication of Identity, Oxford, Littman, pp. 241-256.

Viñas, David (1975). "Gerchunoff, gauchos judíos y xenofobia" en Literatura argentina y realidad política: Apogeo de la oligarquí, Buenos Aires, Siglo XXI, pp. 163-185. 
Orbis Tertius, vol. XXIII, $\mathrm{n}^{\circ}$ 27, e079, junio 2018. ISSN 1851-7811

Viñas, David (1974). Literatura argentina y realidad politica: De Sarmiento a Cortázar, Buenos Aires, Siglo XX.

Wengeroff, Pauline (2010). Memoirs of a Grandmother. Scenes from the Cultural History of the Jews of Russia in the Nineteenth Century, Stanford, Stanford University Press.

Yargina, Z (1993). Wooden Synagogues, Moscú, Image Publishing House.

Zambrano, María (1934). “¿Por qué se escribe?”, en Revista de Occidente, núm.24, pp. 318-328. 